\title{
Variation in circulating immune complex levels with diet, exercise, and sleep: a comparison between normal_controls and patients with systemic lupus erythematosus
}

\author{
D. A. ISENBERG,*A. J. CRISP, W. J. W. MORROW,* D. NEWHAM, \\ AND M. L. SNAITH
}

From the Departments of Haematology, Rheumatology, and Human Metabolism, University College Hospital, and the Department of Immunology, the Middlesex Hospital, London

SUMMARY Circulating immune complexes (CIC) were measured in 4 normal controls and 8 patients with systemic lupus erythematosus (SLE) by a polyethylene glycol precipitation (PEG) method during a 24-hour period. In all the normal controls levels fell during sleep and after drinking 1 pint $(568 \mathrm{ml})$ of milk and rose before getting out of bed and after moderate exercise. There were also marked differences in the patterns of rise and fall of the CIC levels between the normal controls and patients with SLE. Insufficient account has been taken of these physiological influences in CIC levels in previous studies attempting to relate disease activity to quantitative levels.

Levels of circulating immune complexes (CIC) are frequently used as markers of clinical activity in systemic lupus erythematosus (SLE), although early hopes that they might prove to be useful indicators ${ }^{1}$ of inflammatory disease have not been uniformly confirmed. ${ }^{2}$

There is evidence that CIC levels may be altered by the ingestion of food proteins, ${ }^{3}$ and it has been noted that bed rest alone seems to reduce the levels of CIC. This investigation is an attempt to explore the possibility that physiological or circadian variations might explain disparities between the levels of CIC and disease activity. The study was performed by measuring CIC levels over a 24-hour period and examining the effects of feeding, sleep and exercise.

\section{Subjects and methods}

Four healthy volunteers, 2 male and 2 female, age range 21 to 31 years, mean 28 years, and 4 female patients with SLE were venesected via a 21-gauge butterfly needle during a 24-hour period. The CIC levels were measured at 0730,1300 and, $1900 \mathrm{~h}$

*D.A.I. and W.J.W.M. are Sir Jules Thorn research fellows. Accepted for publication 15 December 1980.

Correspondence to Dr D. A. Isenberg, Department of Rheumatology, University College Hospital, London WC1E 6AU.
30 minutes after breakfast, lunch, and supper respectively. Subjects were allowed a free choice of food for lunch and supper but breakfast consisted of 1 pint of milk $(568 \mathrm{ml})$ only. The levels were also measured at 2200 (immediately before going to bed), at 0200 (during sleep), at $\mathbf{0 6 3 0}$ (immediately before rising), at 0700 (30 minutes after rising and just before breakfast), at 0900 , and at $0915 \mathrm{~h}$ (10 minutes after a short period of moderate exercise). One additional patient with SLE went through the above procedure with the exception of the exercise component. The age range of these 5 patients was 25 to 45 years, mean 34 years. Three more female patients with SLE, age range 26 to 35 years, mean 31 years, performed the exercise test only.

Exercise comprised pedalling a bicycle ergometer until the subject's pulse rate was $\frac{2}{3}$ of the maximum for his or her age, as predicted by Åstrand and Rodahl. ${ }^{4}$ This pulse rate was maintained for 3 minutes and the CIC level measured 10 minutes after stopping exercise. Each patient gave her informed consent to the procedures described.

Each of the eight patients satisfied four or more of the American Rheumatism Association criteria ${ }^{5}$ for the classification of SLE. They were each considered to have active disease at the time they were studied.

The CIC levels were measured by a modification ${ }^{6}$ of the polyethylene glycol precipitation technique. ${ }^{7}$ 
The IgG content of the redissolved precipitates was assayed by laser nephelometer (Hyland Laboratories, Thetford, Norfolk). Interassay variation is no greater than $3 \%$. The upper limit of normal, established in 30 healthy volunteers, is $100 \mu \mathrm{g} \mathrm{m}^{-1} \mathrm{IgG}$.

\section{Results}

The levels of CIC in the 4 volunteers are shown in Fig. 1. Those of the 5 patients with SLE who completed most or all of the procedures are shown in Fig. 2. The CIC levels in the three patients who performed the exercise test only are shown in Table 1.

As might be expected, the CIC levels were invariably higher in the patients with SLE than the normal controls. Only on one occasion did a healthy volunteer have a level exceeding our upper limit of normal. There was, however, considerable variation in the CIC levels in both the normal controls and in
Table 1 Levels of circulating immune complexes before and after exercise (normal range less than 100 $\left.\mu g \mathrm{ml}^{-1} \mathrm{IgG}\right)$

\begin{tabular}{lcc}
\hline Patients & Before exercise $0900 h$ & After exercise $0915 h$ \\
\hline 1 & 78.5 & 75.0 \\
2 & 96.8 & 86.3 \\
3 & 288.6 & 275.4 \\
\hline
\end{tabular}

the patients with SLE during the 24-hour period. The largest variation within a single subject among the normal controls was $69.5 \mu \mathrm{gml}^{-1}$ IgG (average variation during 24 hours of the 4 controls was $\left.54.7 \mu \mathrm{gml}^{-1} \mathrm{IgG}\right)$. Among the lupus patients the figures were $289 \mu \mathrm{gml}^{-1} \mathrm{IgG}$ and $141 \cdot 2 \mu \mathrm{gml}^{-1} \mathrm{IgG}$ respectively. Four out of the 5 patients with SLE had at least 1 level of CIC within the normal range recorded during the 24-hour period. The only patient who did not, a 25-year-old woman, had the

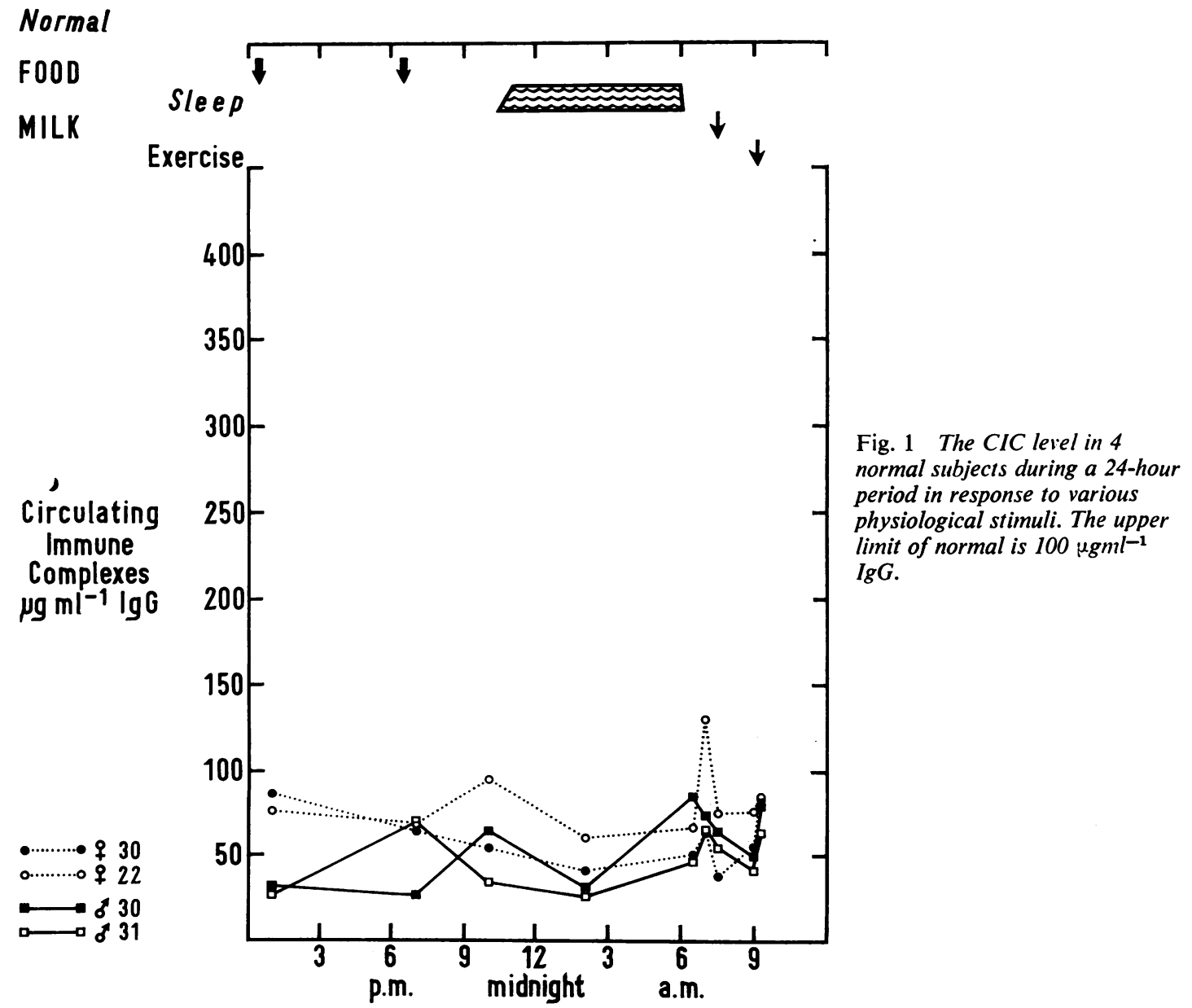




\section{Systemic Lupus Erythematosus.}

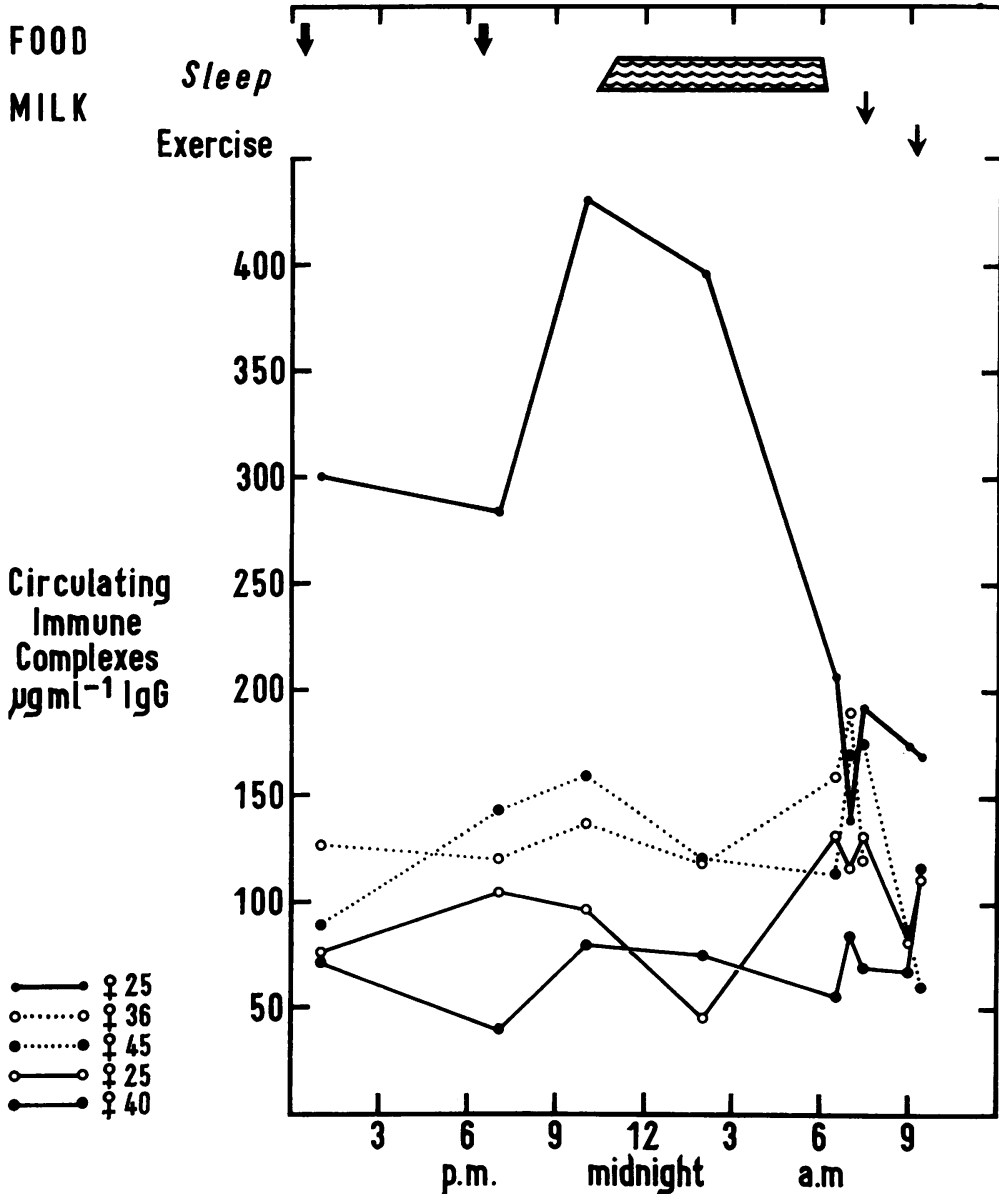

Fig. 2 The CIC levels in 5 patients with SLE during a 24-hour period in response to various physiological stimuli. The upper limit of normal is $100 \mathrm{\mu gml}^{-1} \mathrm{IgG}$.

highest levels of those recorded. During the following 3 months her CIC levels, measured at varying times of day, remained very high but showed considerable fluctuation. Her lowest recorded level in this period was $154 \mu \mathrm{gml}^{-1}$ IgG and the highest $534 \mu \mathrm{gml}^{-1}$ IgG.

Table 2 Trends in the levels of circulating immune complexes

\begin{tabular}{lll}
\hline & $\begin{array}{l}\text { Normal } \\
\text { controls }\end{array}$ & $\begin{array}{l}\text { SLE } \\
\text { patients }\end{array}$ \\
\hline $\begin{array}{l}\text { Fall in the CIC levels between } 1300 \text { and } \\
1900 \mathrm{~h}\end{array}$ & $3 / 4$ & $2 / 5$ \\
$\begin{array}{l}\text { Fall in the CIC levels between } 2200 \text { and } \\
0200 \mathrm{~h}\end{array}$ & $4 / 4$ & $5 / 5$ \\
$\begin{array}{l}\text { Rise in the CIC levels between } 0200 \text { and } \\
0630 \mathrm{~h}\end{array}$ & $4 / 4$ & $2 / 5$ \\
$\begin{array}{l}\text { Rise in the CIC levels } 30 \text { min after rising } \\
\text { Fall in the CIC levels } 30 \text { min after } \\
\quad \text { drinking } 1 \text { pint (568 ml) of milk }\end{array}$ & $3 / 4$ & $3 / 5$ \\
$\begin{array}{l}\text { Rise in the CIC levels } 10 \text { min after } \\
\text { moderate exercise }\end{array}$ & $4 / 4$ & $2 / 5$ \\
\hline
\end{tabular}

The patterns of rise and fall in CIC levels showed some distinctive differences between the 2 groups. However, every subject tested showed a fall in CIC levels between 2200 and $0200 \mathrm{~h}$, the average fall for the normal subjects being $22.3 \mu \mathrm{gml}^{-1}$ IgG and for the lupus group $29.02 \mu \mathrm{gml}^{-1} \mathrm{IgG}$. The major trends in the normal controls are compared with those of the SLE patients in Table 2.

\section{Discussion}

While it is well known that CIC are present in SLE they have also been found in other autoimmune diseases, infectious diseases, parasitic infestations, and also in normal subjects. ${ }^{8}$ It has been suggested that the pathogenicity of CIC may be determined by their size ${ }^{9}$ or the class, subclass, and affinity of the constituent antibody. ${ }^{8}$ Vascular permeability ${ }^{10}$ may also be important. Nevertheless a number of attempts 
have been made to correlate absolute CIC levels with disease activity in SLE. Using fluid phase $\mathrm{Clq}$ binding assays neither Inman et al. ${ }^{2}$ nor Abrass et al. ${ }^{11}$ found any correlation of CIC with disease activity. However, Abrass et al. did find a statistically significant correlation using a solid phase $\mathrm{Clq}$ binding test.

In this study we have shown that physiological mechanisms play a part in determining the level of CIC. The lowering of CIC levels during sleep in all the normal controls and the patients suggests that a circadian rhythm exists. Support for the idea that there is cyclical variation in immunological processes is provided by the work of Cove Smith et al.,12 who showed that the cell mediated response to intradermal tuberculin in normal individuals varied according to the time of day that the challenge was given: the maximal response was at 0700 and the minimal at $2200 \mathrm{~h}$.

Exercise has also been shown to affect the immune response. Short exercise causes a transient lymphocytosis, principally of $\mathrm{B}$ cells. ${ }^{13}$ Long-distance running has also been shown to decrease the response of lymphocytes to $\mathrm{T}$ and $\mathrm{B}$ cell mitogens. ${ }^{14}$

In the present study it has been demonstrated that CIC levels alter after feeding, exercise, and change in posture. These findings may have important practical considerations. Immune complex levels in an inpatient fasted overnight and venesected at $0730 \mathrm{~h}$ before rising may not reasonably be compared with those of an outpatient who has had breakfast or lunch and who has walked up several flights of stairs before venesection. We thus suggest that samples for CIC should be taken under standard conditions; that without such precautions data may be invalidated; and that the search for other influences that impinge on the levels of CIC be continued.

The authors thank Mr Roger Budd for technical assistance, Dr Frank Hay for valuable criticism, Professor R H T Edwards for allowing us his ward facilities for studying the patients, and Jane De Stoop for typing the manuscript.

\section{References}

1 Leading article. Immune complexes in health and disease. Lancet 1977 ; i: $580-1$.

2 Inman R D, Fong J K K, Pussel B A, Hughes G R V. The $C I q$ binding assay in SLE: discordance with disease activity. Ann Rheum Dis 1980; 39: 193.

3 Paganelli R, Levinsky R L J, Brostoff J, Wraith D G. Immune complexes containing food proteins in normal and atopic subjects after oral challenge and effect of sodium cromoglycate on antigen absorption. Lancet 1979; i: $1270-2$.

4 Asstrand P O, Rodahl K. Textbook of work physiology. 2nd ed. London: McGraw Hill, 1976: 352.

5 Cohen A S, Reynolds W E, Franklin E C, et al. Preliminary criteria for the classification of asystemic lupus erythematosus. Bull Rheum Dis 1971 ; 21 : 643-8.

6 Poulton T A, Crowther M E, Hay F C, Nineham L J. Immune complexes in ovarian cancer. Lancet 1978; ii: 72-3.

7 Creighton W D, Lambert P M, Miescher P A. Detection of antibodies and soluble antigen-antibody complexes by precipitation with:polyethylene glycol. J Immunol 1973; lll: 1219-27.

$\varepsilon$ Theofilopoulos A N, Dixon F J. The biology and detection of immune complexes. In: Dixon F J, Kunkel H G, eds. Advances in Immunology. London: Academic Press, 1979; 28: 89-220.

9 Levinsky R J, Cameron J S, Soothill J F. Serum immune complexes and disease activity in lupus nephritis. Lancet 1977; i: 564-7.

10 Lewis E J, Roberts J L. Is autoimmunity a common denominator in immune-complex diseases? Lancet 1980; i: $\mathbf{1 7 8}-\mathbf{8 0}$.

11 Abrass C K, Nies K M, Louie J S, Border W A, Glassock R J. Correlation and predictive accuracy of circulating immune complexes with disease activity in patients with systemic lupus erythematosus. Arthritis Rheum 1980; 23: 273-82.

12 Cove Smith J R, Kabler P, Pownall R, Knapp M S. Circadian variation in an immune response in man. $\mathrm{Br}$ Med J 1978; i' : 253-4.

13 Steel C M, Evans J, Smith M A. Physiological variation in circulating B cell: T cell ratio in man. Nature 1974; 247: 387-9.

14 Eskola J. Ruuskanen O, Soppi E, et al. Effect of sport stress on lymphocyte transformation and antibody formation. Clin Exp Immunol 1978; 32: 339-45. 